\title{
Flora da Bahia: Hypericaceae
}

\author{
Lucas Cardoso Marinho ${ }^{1^{*}}$, André Márcio Amorim ${ }^{1,2, a}$ \& Luciano Paganucci de Queiroz ${ }^{1, b}$ \\ ${ }^{1}$ Programa de Pós-Graduação em Botânica, Universidade Estadual de Feira de Santana, Feira de Santana, Bahia, \\ Brasil. \\ ${ }^{2}$ Departamento de Ciências Biológicas, Universidade Estadual de Santa Cruz, Ilhéus \& Herbário CEPEC, Centro \\ de Pesquisas do Cacau, Itabuna, Bahia, Brasil.
}

\begin{abstract}
Resumo - É apresentado o tratamento das Hypericaceae da Bahia, Brasil, como contribuição ao conhecimento da flora do estado. São reconhecidas uma espécie de Hypericum (H. brasiliense) e quatro de Vismia ( $V$. atlantica, V. guianensis, V. martiana e V. pentagyna). São fornecidas descrições, ilustrações, comentários e mapas de distribuição das espécies na Bahia. São indicados os sinônimos mais frequentemente encontrados nos herbários da Bahia.

Palavras-chave adicionais: florística, Hypericum, Malpighiales, Nordeste do Brasil, Vismia.
\end{abstract}

\begin{abstract}
Flora of Bahia: Hypericaceae) - The treatment of the Hypericaceae from Bahia, Brazil, is presented as a contribution to the knowledge of the flora of the state. One species of Hypericum (H. brasiliense) and four of Vismia (V. atlantica, V. guianensis, V. martiana e $V$. pentagyna) are recognized. Descriptions, illustrations, notes, and distribution maps of species in Bahia are provided. The synonyms that are more often found in the Bahian herbaria are indicated.
\end{abstract}

Additional key words: floristics, Hypericum, Malpighiales, Northeast Brazil, Vismia.

\section{HYPERICACEAE}

Árvores, arvoretas, arbustos, subarbustos a ervas anuais; ramos glabros ou indumentados, exsudato (presente ou não) amarelo-claro a avermelhado. Folhas opostas ou verticiladas, simples, margens inteiras, membranáceas, cartáceas ou coriáceas, glabras ou indumentadas na face abaxial, sem estípulas, com glândulas ou não, sésseis ou pecioladas. Inflorescências terminais multifloras, cimosas, paniculadas ou com flores solitárias. Flores bissexuadas, homo ou heterostilas, actinomorfas, subsésseis a pediceladas, diclamídeas; sépalas (4)5(-8), livres ou conatas, persistentes, glabras ou indumentadas, glândulas presentes ou não; pétalas (4)5(-8), livres, geralmente contortas, glabras ou indumentadas, glândulas presentes ou não; estames 1 a muitos, fasciculados ou dispostos em um anel contínuo ao redor do ovário, estaminódios presentes ou não, filetes conatos ou livres, anteras rimosas; ovário súpero, (2-)5(-8)-carpelar, 1- ou 5locular, placentação axial ou parietal, muitos óvulos por lóculo, estiletes (2)3-5(-8), livres, estigmas disciformes ou capitados. Frutos bagas ou cápsulas septicidas. Sementes muitas, creme ou castanhas, não aladas.

Hypericaceae abrange nove gêneros e cerca de 565 espécies e possui distribuição cosmopolita (Stevens 2016). No Brasil, são reconhecidas 24 espécies de Hypericum (Vogel Ely et al. 2015; Vogel Ely \& Boldrini 2015) e 29 de Vismia (Bittrich et al. 2015; Marinho et al. 2016), ambos os gêneros representados na Bahia.

\footnotetext{
*Autor para correspondência: lcmarinho1@gmail.com;

aamorim.uesc@gmail.com; bluciano.paganucci@gmail.com

Editor responsável: Alessandro Rapini

Submetido: 27 abr. 2016; aceito: 20 jul. 2016

Publicação eletrônica: 12 ago. 2016; versão final: 19 ago. 2016
}

\section{Chave para as espécies}

1. Subarbustos, exsudato ausente; folhas sésseis, glabras; sépalas e pétalas glabras; frutos cápsulas septicidas ................... 1.1. Hypericum brasiliense

1'. Árvores, arvoretas ou arbustos, exsudato presente; folhas pecioladas, geralmente indumentadas; sépalas e pétalas indumentadas; frutos bagas ...........

2. Vismia

2. Lâmina foliar $>13,5 \mathrm{~cm}$ compr., mais de 18 pares de nervuras secundárias; fascículos de estames com indumento lanoso, persistentes no fruto .....

2.1. $V$. atlantica

2'. Lâmina foliar $<13,5 \mathrm{~cm}$ compr., menos de 16 pares de nervuras secundárias; fascículos de estames com tricomas esparsos, não persistentes no fruto.

3. Flores heterostilas; pétalas sem canais ou pontuações glandulares; sépalas adpressas no fruto maduro ................. 2.2. $\mathrm{V}$. guianensis

3'. Flores homostilas; pétalas com canais ou pontuações glandulares; sépalas reflexas ou patentes no fruto maduro.

4. Lâmina foliar com face abaxial velutina e coloração marrom-escura in sicco; sépalas patentes no fruto maduro ............. 2.3. V. martiana

4'. Lâmina foliar com face abaxial tomentosa e coloração creme in sicco; sépalas fortemente reflexas no fruto maduro .........

2.4. V.pentagyna

\section{Hypericum $\mathrm{L}$.}

Árvores a ervas anuais; ramos glabros ou raramente indumentados, glândulas punctiformes presentes ou não, sem exsudato. Folhas opostas ou verticiladas, sésseis, com glândulas punctiformes; 
lâmina glabra ou raramente indumentada. Inflorescências cimosas ou com flores solitárias. Flores subsésseis ou pediceladas; sépalas glabras, raramente indumentadas; pétalas geralmente contortas, amarelas a alaranjadas; estames 1 a muitos; ovário com placentação parietal, (2-)5(-8) estiletes livres. Frutos cápsulas septicidas. Sementes estriado-escalariformes.

Hypericum possui cerca de 500 espécies, distribuídas principalmente em regiões com baixas temperaturas, em todo o globo (Robson 2012), mas predominantemente no hemisfério Norte (Meseguer et al. 2013). No Brasil, ocorrem 24 espécies distribuídas principalmente nas Regiões Sudeste e Sul (Vogel Ely et al. 2015).

1.1. Hypericum brasiliense Choisy in DC., Prodr. 1: 547.1824.

Figuras 1 e 2.

Subarbustos até $1 \mathrm{~m}$ alt.; ramos jovens angulosos. Folhas $0,9-1,6 \times 0,3-0,6 \mathrm{~cm}$, patentes, membranáceas a cartáceas, elípticas a lineares, margens inteiras, ápice agudo, base atenuada, nervura central proeminente na face abaxial, glândulas punctiformes pouco evidentes. Inflorescências 3-18-floras; brácteas e bractéolas 2-5 $\mathrm{mm}$ compr., lanceoladas a lineares. Flores com pedicelo 2-3 mm compr.; sépalas 5-7 × 1,5-2 mm, lanceoladas, margens inteiras, ápice agudo a subulado, base truncada, persistentes; pétalas 7-9 × 2,5-5 mm, membranáceas, obovais a oblongas, margens pouco onduladas no ápice, ápice arredondado a subacuminado, base truncada, glândulas lineares; estames numerosos, amarelos, dispostos em um anel contínuo ao redor do ovário; ovário ca. 1,5 mm compr., estiletes ca. 3,5 mm compr., persistentes, estigma captado. Cápsulas 1-1,2 cm compr., ovais.

Hypericum brasiliense ocorre com maior abundância nas Regiões Sudeste e Sul (Bittrich et al. 2015), em áreas abertas, ainda que imersas em áreas de floresta (Vogel Ely, com. pess.). G7: floresta estacional semidecidual, entre 700 e 900 m s.n.m. Encontrada com frutos em março.

Material examinado - Barra do Choça, estrada para Itapetinga, 14 54 'S, 40³4'W, 30 mar. 1977 (fr.), R.M. Harley 20173 (CEPEC)

Material adicional examinado - BRASIL. PARANÁ: Balsa Nova, São Luís do Purunã, 10 dez. 2013 (fl.), F. França \& E. Melo 5083 (HUEFS). SANTA CATARINA: Lajes, Distrito de Índios, 15 dez. 1967 (fl.), A. Lourteig 2235 (CEPEC). SÃO PAULO: Itapeva, Estação Ecológica Banhado, 244'S, 49²'W, 27 jan. 2009 (fl.), J.B. Baitello et al. 2220 (HUEFS).

A região sudoeste da Bahia, onde foi obtido o único registro de $H$. brasiliense para o estado, é pouco explorada floristicamente. Há, ainda, um acelerado crescimento de áreas de pastagem e monocultura na região e, desta forma, supõe-se que a população conte atualmente com poucos indivíduos. O registro na Bahia apresenta apenas frutos; para a descrição dos caracteres florais, foram utilizados materiais complementares de outros estados.

\section{Vismia Vand.}

Árvores, arvoretas ou arbustos; ramos com tricomas ferrugíneos dendríticos ou estrelados, exsudato amarelo a alaranjado. Folhas pecioladas, opostas, discolores; lâmina com face abaxial ferrugínea ou creme, glabra ou indumentada. Inflorescências terminais, paniculadas. Flores homo ou heterostilas; sépalas ferrugíneas, esverdeadas ou acinzentadas, margens membranáceas, quincunciais, indumentadas, glândulas em pontuações e/ou canais presentes ou ausentes; pétalas contortas ou simétricas, face adaxial parcial ou completamente lanosa, com pontuações e/ou canais glandulares frequentemente visíveis na face abaxial; fascículos de estames indumentados, persistentes ou não, filetes com porção distal livre; nectários estaminodiais lanosos; placentação axial, estiletes 5 livres, geralmente persistentes, estigmas disciformes. Frutos bagas lisas, coriáceas. Sementes foveoladas.

Vismia possui 65 espécies e distribuição tropical, ocorrendo desde o México até o sul do Brasil (Kearns et al. 1998). No Brasil, ocorrem 29 espécies, distribuídas em todas as Regiões (exceto no extremo sul), com predominância na Amazônia (Bittrich et al. 2015). Na Bahia, Bittrich et al. (2015) citaram quatro espécies de Vismia. No entanto, V. macrophylla Kunth é endêmica da floresta amazônica e não foi incluída neste tratamento, enquanto $V$. atlantica foi recentemente descrita para o estado (Marinho et al. 2016). Além de $V$. atlantica, ocorrem na Bahia $V$. guianensis, $V$. martiana e $V$. pentagyna.

2.1 Vismia atlantica L.Marinho \& M.V.Martins, J. Torrey Bot. Soc. 143(3): 331. 2016.

Figuras 2, 3A-H e $5 \mathrm{~A}-\mathrm{C}$.

Árvores ou arbustos, até $12 \mathrm{~m}$ alt.; ramos densamente pubescentes com tricomas ferrugíneos, dendríticos e estrelados, exsudato alaranjado. Folhas com pecíolo 15-22 mm compr.; lâmina 13,5-29 × 5,5$9,5 \mathrm{~cm}$, cartácea a coriácea, oval a lanceolada, margens inteiras e/ou onduladas, ápice agudo, base cordada a arredondada, face adaxial verde e brilhante in vivo, marrom-clara in sicco, face abaxial verde-oliva in vivo, ferrugínea in sicco, nervuras secundárias (18-29 pares) e intersecundárias fortemente proeminentes, tomentosa, com tricomas dendríticos e estrelados adensados, glândulas nigrescentes cobertas por tricomas na face abaxial. Flores homostilas; pedicelo 1,5-2,5 $\mathrm{mm}$ compr.; sépalas 6-6,5 × 2,5-3 $\mathrm{mm}$, castanhas, com tricomas ferrugíneos, lanceoladas a ovais, ápice agudo a arredondado, base truncada, com canais glandulares visíveis na face abaxial; pétalas 9-10 × 4,5-5 mm, verde-claras, levemente contortas e reflexas, lanceoladas, ápice arredondado, base atenuada, face adaxial lanosa, face abaxial com pontuações glandulares castanhas a arroxeadas; fascículos de estames 8-11 mm compr., base mais larga e plana, completamente cobertos por indumento lanoso, persistentes; nectários ca. $2,5 \mathrm{~mm}$ compr., ovais; 

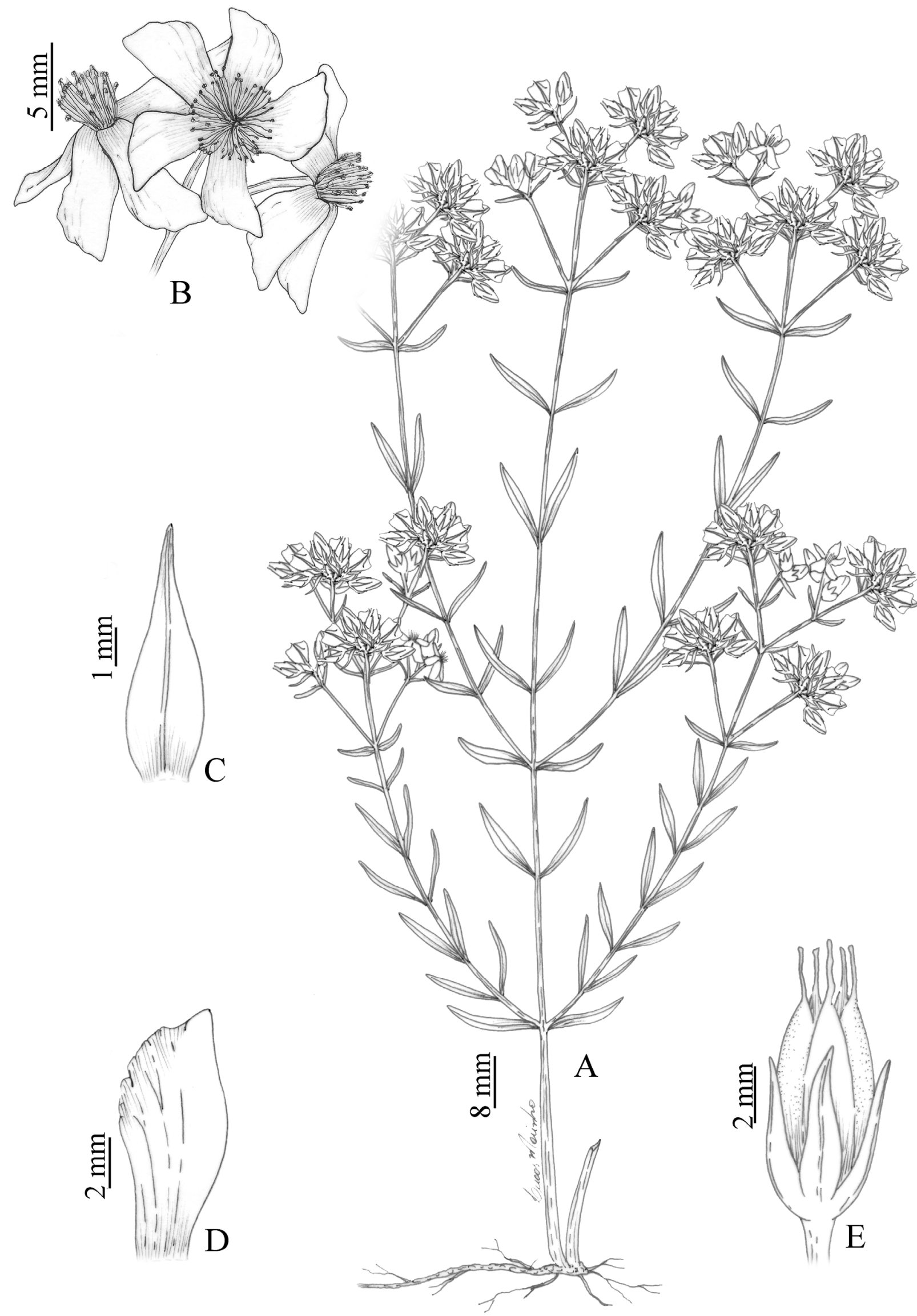

Figura 1. Hypericum brasiliense: A- hábito; B- flores; C- sépala, vista abaxial; D- pétala, vista adaxial; E- fruto (A-D- França \& Melo 5083; E- Harley 20173). 


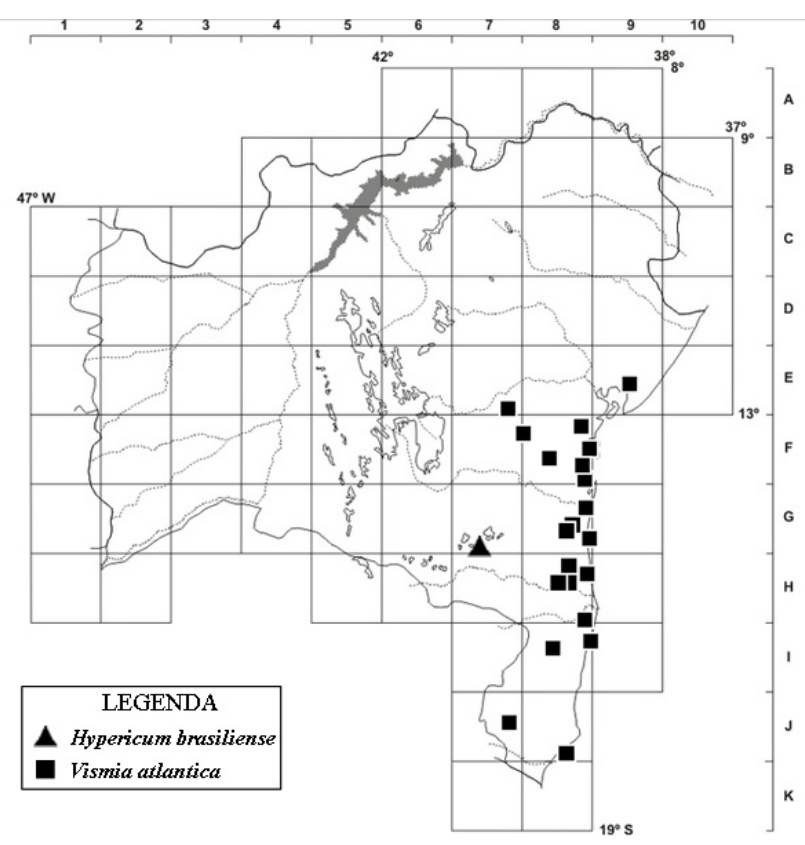

Figura 2. Mapa de distribuição geográfica de Hypericum brasiliense e Vismia atlantica no estado da Bahia.

estiletes ca. $2 \mathrm{~mm}$ compr., geralmente persistentes, ovário ca. 2,5 mm compr., oval. Bagas 1-1,2 cm compr., ovais; sépalas \pm patentes no fruto maduro.

Vismia atlantica ocorre no norte do Espírito Santo e, na Bahia, com maior abundância nas florestas do sul do estado. E7, F7, J7, F8, G8, H8, I8, J8, E9: floresta ombrófila montana e submontana. Floresce entre os meses de agosto e janeiro, com frutificação de setembro a julho.

Material selecionado - Amargosa, Serra do Timbó, 13ำ's, 3909’W, 25 jan. 2007 (fl. e fr.), D. Cardoso et al. 1583 (HUEFS); Arataca, Serra do Peito de Moça, 15¹0'S, 39²0’W, 19 jan. 2007 (fr.), A.M. Amorim et al. 6669 (CEPEC, HUEFS); Belmonte, Ramal para o rio Ubu, $15^{\circ} 57^{\prime} \mathrm{S}, 39^{\circ} 06^{\prime} \mathrm{W}, 27$ set. 1979 (fl.), L.A. Mattos-Silva et al. 609 (CEPEC); Cairu, rodovia Nilo Peçanha-Cairu, 1329'S, 3902'W, 9 dez. 1980 (fr.), A.M. Carvalho et al. 373 (ALCB, CEPEC, HRB); Camacan, Rio Branco, 15²5'S, 39²9'W, 11 jul. 1964 (fr.), C.M.M. \& N.M.P. 92 (CEPEC); Camamu, Barcelos do Sul, 1356'S, 3906'W, 18 jul. 2005 (bot.), A.M. Miranda \& M.I. Silva 5166 (HUEFS); Entre Rios, RPPN Fazenda Lontra/Saudade, $12^{\circ} 54^{\prime} \mathrm{S}$, 40¹2'W, 21 set. 1997 (fr.), N.G. Jesus 140 (HUESC); Eunápolis, BR-5, 16²2'S, 39³4'W, 28 set. 1966 (fl.), R.P. Bélem \& R.S. Pinheiro 2647 (CEPEC); Ilhéus, fazenda Nossa Senhora de Fátima, 1447’S, 3902'W, 25 mar. 1997 (fr.), L.A. Mattos-Silva et al. 3525 (ALCB, CEPEC, HUEFS, HUESC); Itacaré, fazenda Capitão,

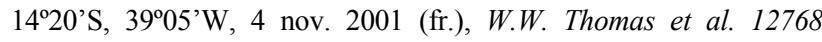
(CEPEC); Itajuípe, rodovia Banco Central, $14^{\circ} 40^{\prime} \mathrm{S}, 39^{\circ} 22^{\prime} \mathrm{W}, 18$ nov. 1971 (fl.), T.S. Santos 2179 (CEPEC); Ituberá, fragmento da fazenda Biriba, $13^{\circ} 43^{\prime} \mathrm{S}, 39^{\circ} 08^{\prime} \mathrm{W}, 23$ set. 2006 (fl.), R. Valadão \& M.L. Guedes 728 (ALCB); Medeiros Neto, agrovila Panorama, 17²6'S, 40¹1'W, 18 dez. 2008 (fl.), L.S. Almeida et al. 10 (HUEFS); Nova Viçosa, Aracruz, 1753'S, 39²2'W, 22 ago. 1993 (fl.), M.L. Guedes et al. 2582 (HUEFS); Santa Cruz Cabrália, 16 16's, 3901'W, 17 maio 1994 (fr.), M.L. Guedes et al. 3142 (ALCB); Santa Luzia, fazenda Córrego Verde, $15^{\circ} 25^{\prime}$ 'S, 39²0'W, 15 jun. 1988 (bot.), L.A. Mattos-Silva et al. 2443 (ALCB, CEPEC, HRB, HUEFS); São
Sebastião do Passé, fazenda Panema, 12³3'S, 38²3'W, 27 mar. 2001 (est.), G. Carvalho et al. 24 (ALCB, CEPEC); Una, REBIO do Mico-leão, 15²1'S, 3904'W, 14 set. 1993 (fl.), A.M. Amorim et al. 1381 (ALCB, CEPEC, HRB, HUEFS); Uruçuca, Serra Grande, 14 35'S, 39 $17^{\circ}$ 'W, 7 set. 1991 (bot.), A.M. Carvalho et al. 3653 (CEPEC, HUEFS); Valença, estrada para Maricultura, $13^{\circ} 16^{\prime} \mathrm{S}$, 3959'W, 30 out. 2011 (fr.), E. Matos \& G. Vidal 710 (CEPEC, HUEFS); Wenceslau Guimarães, assentamento Oziel Alves, 13³7'S, 39³7'W, 13 ago. 2001 (fl.), D.L. Santana et al. 763 (ALCB).

Vismia atlantica vinha sendo equivocadamente identificada nos herbários da Bahia e Espírito Santo como $V$. macrophylla, espécie endêmica da floresta amazônica (Marinho et al. 2016). Das espécies ocorrentes na Bahia, $V$. atlantica pode ser diferenciada pelo acentuado número de nervuras secundárias (18-29 pares; Figuras 3B e 5A) e pelos fascículos de estames persistentes no fruto (Figura $3 \mathrm{H}$ ).

2.2. Vismia guianensis (Aubl.) Pers., Syn. Pl. 2: 86. 1807.

$=$ Vismia ferruginea Kunth in HBK, Nov. Gen. Sp. (quarto ed.) 5: 183. 1821 [1822].

= Vismia reichardtiana (Kuntze) Ewan, Contr. U.S. Natl. Herb. 35(5): 348. 1962.

Figuras 3I-O, 4 e 5D-I.

Árvores ou arbustos até $6 \mathrm{~m}$ alt.; ramos densamente pubescentes com tricomas ferrugíneos dendríticos e estrelados, exsudato amarelo a alaranjado. Folhas com pecíolo 7-15 mm compr.; lâmina 7-13,5 × 2-5 cm, cartácea a coriácea, elíptica a lanceolada, margens inteiras e/ou onduladas, ápice acuminado a agudo, base arredondada a atenuada, face adaxial verde-escura in vivo, marrom-clara in sicco, face abaxial ferrugínea in vivo e in sicco, glabra ou com tricomas dendríticos e estrelados, nervuras secundárias $(8-12$ pares $) \mathrm{e}$ intersecundárias pouco proeminentes, tomentosa, com tricomas dendríticos e estrelados, e glândulas nigrescentes na face abaxial. Flores heterostilas; pedicelos 3-5 mm compr.; sépalas 6-7 × 3-3,5 mm, castanhas a esverdeadas, cobertas por tricomas ferrugíneos, lanceoladas, ápice agudo, base truncada, sem glândulas; pétalas 8-9 × 2,5-4 $\mathrm{mm}$, verdes, contortas, lanceoladas a obovais, ápice arredondado, base atenuada, face adaxial lanosa, face abaxial sem canais e pontuações glandulares; fascículos de estames 7-8 mm compr., com tricomas esparsos na base, não persistentes; nectários ca. $2 \mathrm{~mm}$ compr., ovais; estiletes 1-5 mm compr., geralmente persistentes, ovário 3-5 mm compr., oval. Bagas 1-1,3 cm compr., arredondadas a ovais; sépalas adpressas no fruto maduro.

Vismia guianensis ocorre nas Regiões Norte e Nordeste (Bittrich et al. 2015). D6, E6, F6, C7, D7, F7, E8, F8, G8, I8, J8, E9, F9, H9, D10, E10: caatinga, campo rupestre, floresta ombrófila montana e submontana, restinga e floresta estacional. As flores e frutos podem ser vistos durante todo o ano, com período intenso de floração entre dezembro e fevereiro, e de frutificação entre fevereiro e março. 


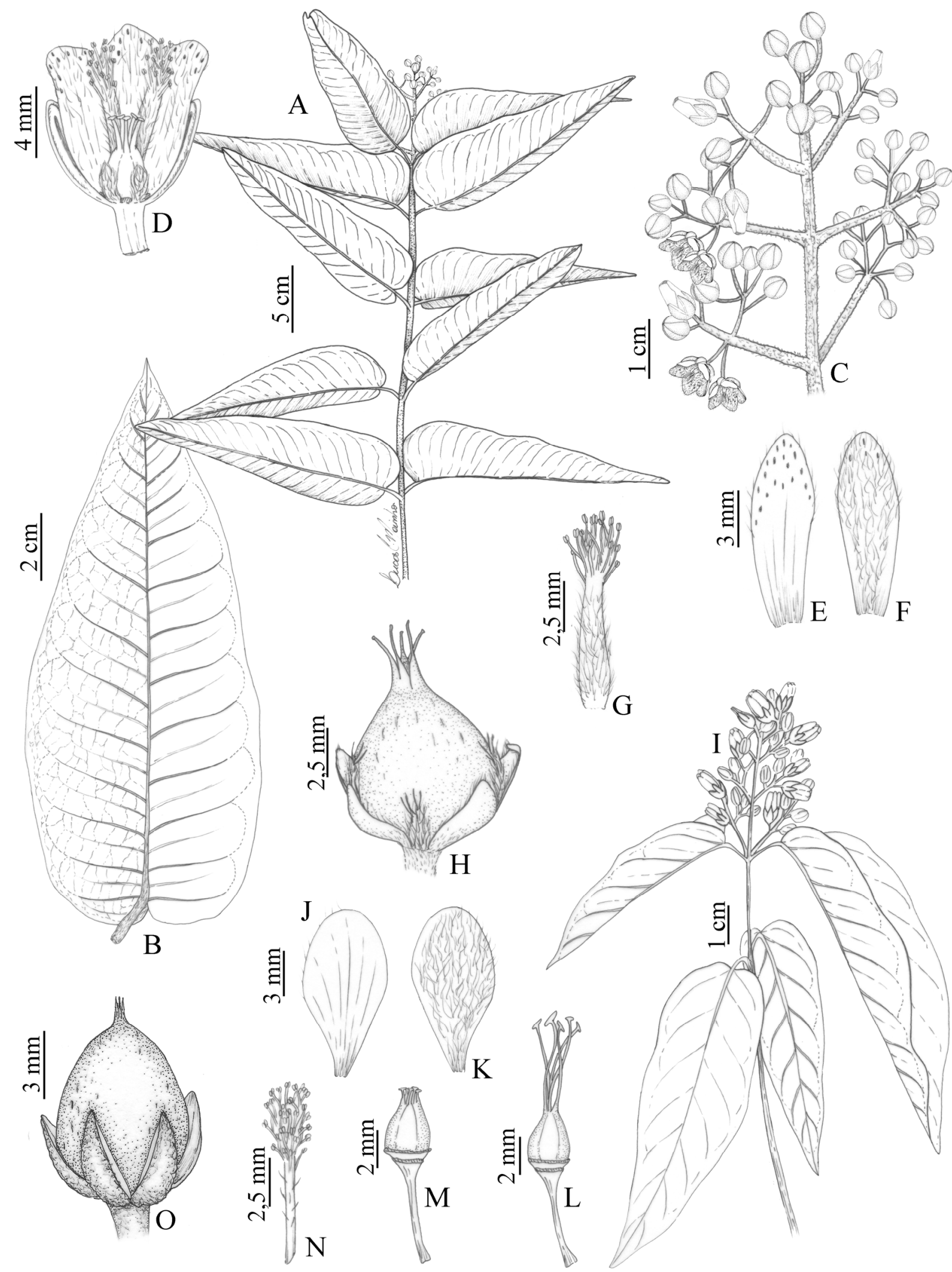

Figura 3. A-H. Vismia atlantica: A- ramo com folhas em vista abaxial; B- face abaxial da lâmina foliar; C- inflorescência com botões e flores; D- flor com duas sépalas e pétalas retiradas; E- pétala, vista abaxial; F- pétala, vista adaxial; G- fascículo de estames; H- fruto. I-O. V. guianensis: I- ramo com inflorescência; J- pétala, vista abaxial; K- pétala, vista adaxial; L- gineceu de flor longistila; M- gineceu de flor brevistila; N- fascículo de estames; O- fruto. (A-G- Cardoso et al. 1583; H- Marinho et al. 959; I-O- Marinho et al. 592).

Material selecionado - Alagoinhas, Campus II/UNEB, HUEFS); Amargosa, Serra do Timbó, 13²10'S, $39^{\circ} 09^{\prime} \mathrm{W}, 28$ abr. 1208'S, 3809’W, 17 fev. 1998 (fr.), L.C.L. Lima et al. 79 (ALCB, 2007 (fl. e fr.), J.L. Paixão et al. 1159 (HUEFS); Amélia 


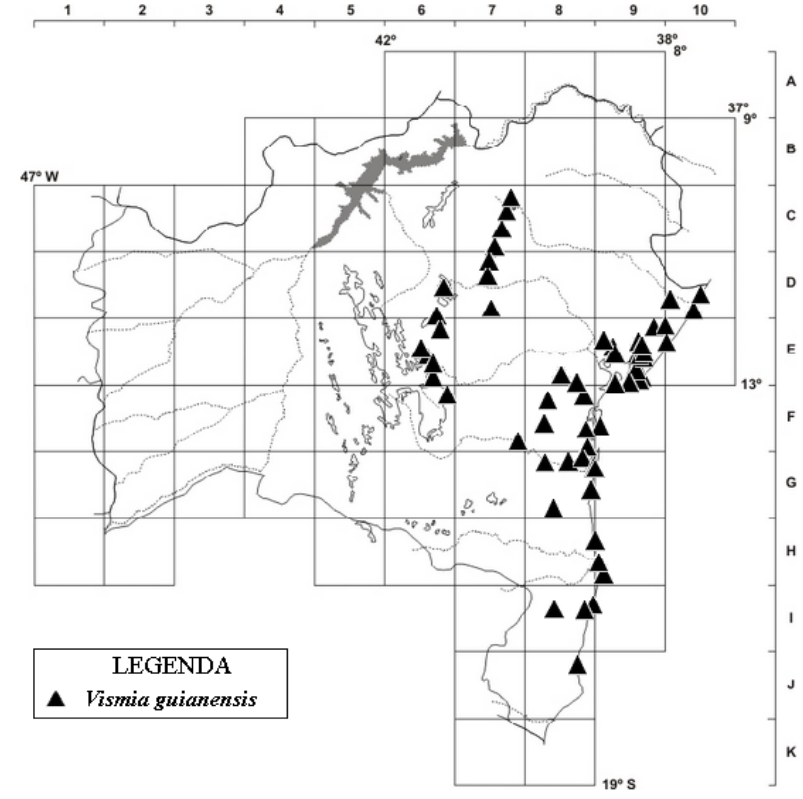

Figura 4. Mapa de distribuição geográfica de Vismia guianensis no estado da Bahia.

Rodrigues, $12^{\circ} 26^{\prime}$ S, $38^{\circ} 44^{\prime}$ 'W, 20 mar. 1987 (fr.), L.P. Queiroz \& I.A. Crepaldi 1449 (HUEFS); Andaraí, Igatu, 1253'S, 41¹8'W, 5 fev. 1999 (fl. e fr.), E.B. Miranda et al. 67 (HUEFS); Belmonte, Barrolândia, 1551'S, 3852'W, 5 set. 2003 (fr.), L.A. Mattos-Silva et al. 4746 (CEPEC); Bonito, Córrego do Brejo, $11^{\circ} 58^{\prime} \mathrm{S}, 41^{\circ} 15^{\prime} \mathrm{W}$, 5 dez. 2013 (fl.), L.C. Marinho et al. 592 (HUEFS); Cairu, Ilha de Boipeba, 133' S, 38 55 'W, 18 ago. 2008 (est.), A.M. Amorim et al. 7659 (CEPEC); Camaçari, Arembepe, $12^{\circ} 56^{\prime} \mathrm{S}, 38^{\circ} 21^{\prime} \mathrm{W}, 4$ fev. 2006 (fl.), D. Cardoso et al. 1132 (HUEFS); Camamu, Barra Grande, 135' 'S, 39 $06^{\prime} \mathrm{W}, 8$ nov. 2010 (bot.), G. Costa et al. 508 (MBML); Campo Formoso, Tuiutiba, $10^{\circ} 24^{\prime} \mathrm{S}, 40^{\circ} 15^{\prime} \mathrm{W}, 17 \mathrm{fev}$. 2006 (fr.), F. França et al. 5432 (HUEFS); Canavieiras, Canavieiras/Santa Luzia, 1540’S, 3856”W, 21 jan. 1998 (fl.), A.M. Amorim et al. 2124 (CEPEC); Castro Alves, Serra da Jiboia, $12^{\circ} 51^{\prime} \mathrm{S}, 39^{\circ} 28^{\prime} \mathrm{W}, 27$ maio 1987 (fr.), L.P. Queiroz et al. 1585 (HUEFS); Catu, 12²1'S, 38²2'W, 24 maio 1997 (fr.), M.M. Silva \& T.S.N. Sena 63 (HUEFS); Conde, fazenda Cezo, 1153'S, 37³5'W, 29 jul. 2011 (fr.), E. Matos et al. 296 (HUEFS); Dias d'Ávila, 12³6'S, 387' W, 13 dez. 1971 (bot.), A.L. Costa s.n. (ALCB 2793, HUEFS 15471); Entre Rios, estrada para Imbé, $12^{\circ} 07^{\prime} \mathrm{S}, 37^{\circ} 59^{\prime} \mathrm{W}, 16$ nov. 2005 (bot.), T.S. Nunes et al. 1294

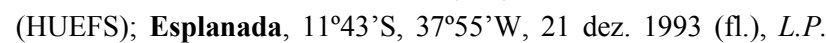
Queiroz \& N.S. Nascimento 3772 (HUEFS); Eunápolis, Alecrim, 16²2'S, 39³4'W, 10 jan. 1997 (bot.), M.L. Guedes et al. 4123 (ALCB); Feira de Santana, 12²0'S, 3852'W, 5 jun. 2012 (fl.), E.A. Santos et al. 40 (HUEFS); Ibicaraí, fazenda Estância Manacá, $14^{\circ} 51^{\prime}$ 'S, 39 $35^{\circ}$ 'W, 18 jun. 2004 (fr.), R.N. Querino et al. 23 (CEPEC); Ibirapitanga, fazenda Paineiras, $14^{\circ} 09^{\prime} \mathrm{S}, 39^{\circ} 22^{\prime} \mathrm{W}, 17$ fev. 1998 (bot.), A.S. Conceição 221 (HRB, HUEFS); Ilhéus, Ponta da Tulha, 14³5'S, 3903'W, 26 jun. 2009 (fr.), C.N. Fraga et al. 2582 (HUEFS); Itabuna, $14^{\circ} 15^{\prime} \mathrm{S}, 39^{\circ} 01^{\prime} \mathrm{W}, 1$ abr. 1974 (f.), R.M. Harley 17598 (CEPEC); Itacaré, 14'16'S, 3859'W, 7 jun. 1978 (fr.), S.A. Mori \& T.S. Santos 10165 (CEPEC); Itaeté, Paraguaçu,

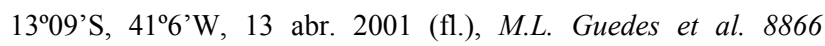

(ALCB, CEPEC); Itagibá, Mata da Antena, $14^{\circ}$ '00'S, 39²'’ W, 10 jul. 2008 (fr.), C.E. Ramos et al. 182 (ALCB); Itanagra, Núcleo Agroecológico de Nova Itapecirica, 12²2'S, 3758'W, 31 jan. 2009 (f1.), A.R. Prates et al. 195 (ALCB); Ituberá, Fazendas Reunidas Vale do Juliana, $13^{\circ} 40^{\prime}$ S, $39^{\circ} 07^{\prime}$ W, 7 fev. 2004 (fl.), J.G. Carvalho-

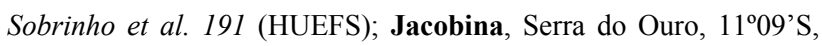
$40^{\circ} 30^{\prime} \mathrm{W}, 6$ jun. 2001 (fl.), T.S. Nunes et al. 361 (HUEFS);

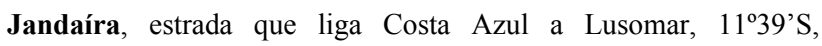
37²9'W, 19 abr. 2004 (fl.), T. Ribeiro et al. 511 (CEPEC, HRB);

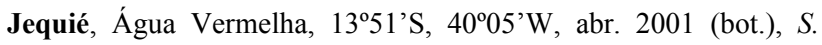
Correia s.n. (ALCB 55224); Lamarão, 12³4'S, 38 $211^{\prime} \mathrm{W}, 10 \mathrm{dez}$. 2002 (bot.), M.L. Guedes \& D.M. Loureiro 9759 (ALCB); Lauro de Freitas, $12^{\circ} 53^{\prime}$ 'S, 38 $19^{\prime} \mathrm{W}, 13$ mar. 1989 (fl.), R. Soeiro 60 (HRB);

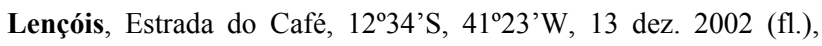
M.S. Castro et al. 601 (HUEFS); Maraú, Península de Campinho, 1406'S, 3900'W, 30 dez. 1999 (fl.), D.S. Carneiro-Torres et al. 197 (HUEFS); Mata de São João, Praia do Forte, 12³1'S, $38^{\circ} 17^{\prime}$ W, 1 ago. 2004 (bot.), E.P. Queiroz 2962 (ALCB, HRB, HUEFS); Miguel Calmon, Parque de Sete Passagens, $11^{\circ} 22^{\prime} \mathrm{S}$, $40^{\circ} 31^{\prime} \mathrm{W}, 11$ mar. 2006 (bot.), V.J. Santos et al. 458 (HUEFS); Morro do Chapéu, Cachoeira do Ferro Doido, $11^{\circ} 33$ 'S, $41^{\circ} 09^{\prime} \mathrm{W}, 5$ out. 2007 (fl.), L.C.P. Lima et al. 414 (HUEFS); Mucugê, 12²41'S, $41^{\circ} 18^{\prime}$ W, mar. 2008 (fl.), C.M. Pigozzo 225 (HUEFS); Mundo Novo, serra vizinha à cidade, $11^{\circ} 51^{\prime} \mathrm{S}, 40^{\circ} 28^{\prime} \mathrm{W}, 29$ abr. 1972 (fr.), A.L. Costa s.n. (ALCB 2794, HUEFS 15472, VIES 8003); Palmeiras, estrada para Lençóis, 12²7’S, 4128' W, 5 jul. 1998 (fl. e fr.), P.P. Oliveira \& R.C. Araújo 10 (HUEFS); Pindobaçu, Serra da Fumaça, 1040'S, 40¹9'W, 9 fev. 2009 (fr.), L.A. Sousa \& L.G. Mello 248 (HUEFS); Pojuca, Mariquita, 12²5'S, 38 $18^{\circ} 9^{\prime} \mathrm{W}, 9 \mathrm{dez}$. 2002, C.S. Silva-Lima 117 (ALCB, HUEFS); Porto Seguro, Trancoso, 16 23 'S, 3908'W, 4 out. 1997 (fr.), M.L. Guedes \& M.A. Batista 5347 (ALCB); Prado, fazenda Riacho das Ostras, 17²1'S, $39^{\circ} 14^{\prime}$ W, 28 nov. 2006 (fr.), S.G. Rezende \& E.G. Rezende 1732 (HUEFS); Salvador, Boca do Rio, 1258'S, 38³0'W, 25 maio 1980 (bot.), L.R. Noblick 1815 (ALCB, HUEFS); Santa Cruz Cabrália, $16^{\circ} 18^{\prime}$ 'S, 39 $01^{\circ}$ 'W, 11 out. 1999 (fr.), B.M. Silva et al. 27 (HUEFS); Santa Teresinha, Serra da Jiboia, $12^{\circ} 15^{\prime}$ 'S, $39^{\circ} 28^{\prime} \mathrm{W}, 27$ jul. 2000 (fr.), J.G.C. Sobrinho 6 (HUEFS); Santo Amaro, 12²3's, $38^{\circ} 42^{\prime}$ W, 27 dez. 1976 (bot.), Pereira-de-Souza s.n. (ALCB 10738); Santo Antônio de Jesus, 12 $58^{\prime}$ 'S, 39² $15^{\prime}$ W, 23 fev. 1975 (bot.), A.L. Costa s.n. (ALCB 2790, HUEFS 15474); Saúde, Serra do Espinhaço, 10 $0^{\circ} 56^{\prime} \mathrm{S}, 40^{\circ} 25^{\prime} \mathrm{W}, 28$ mar. 2009 (fl.), E.P. Queiroz 3671 (HRB); Senhor do Bonfim, Piemonte Diamantina, $10^{\circ} 22^{\prime} \mathrm{S}$, $40^{\circ} 11^{\prime}$ W, 15 nov. 2005 (bot.), P.E.M.A. Silva 26 (ALCB); Simões Filho, Góes Calmon, 1247'S, 38²4'W, 24 jun. 1999 (fl.), J. Costa \& C.B. Nascimento 253 (HRB); São Sebastião do Passé, 12³3'S, $38^{\circ} 23^{\prime} \mathrm{W}, 27$ mar. 2001 (fr.), G. Carvalho et al. 24 (ALCB, CEPEC); Ubaíra, estrada para Santa Inês, $13^{\circ} 14^{\prime} \mathrm{S}, 39^{\circ} 40^{\prime} \mathrm{W}, 10$ mar. 2008 (fr.), R.P. Oliveira et al. 1464 (HUEFS); Una, fazenda Bolandeira, 15²0'S, 38 59' W, 25 nov. 2004 (bot.), L.A. MattosSilva et al. 4858 (HUEFS); Utinga, 9 km de Riachão em direção a Bonito, $12^{\circ} 00^{\prime} \mathrm{S}, 41^{\circ} 12^{\prime} \mathrm{W}, 10$ abr. 1986 (fl.), A.C. Sarmento \& H.P. Bautista 874 (ALCB, HRB, HUEFS); Vera Cruz, Distrito de Baiacu, 1259'S, 38²'W, 23 fev. 2002 (fl.), M.V. Moraes 499 (HUEFS); Wenceslau Guimarães, Estação Ecológica Nova

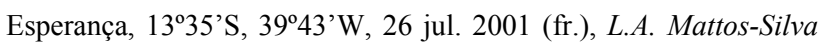
et al. 4414 (ALCB, BAH, HUEFS). 

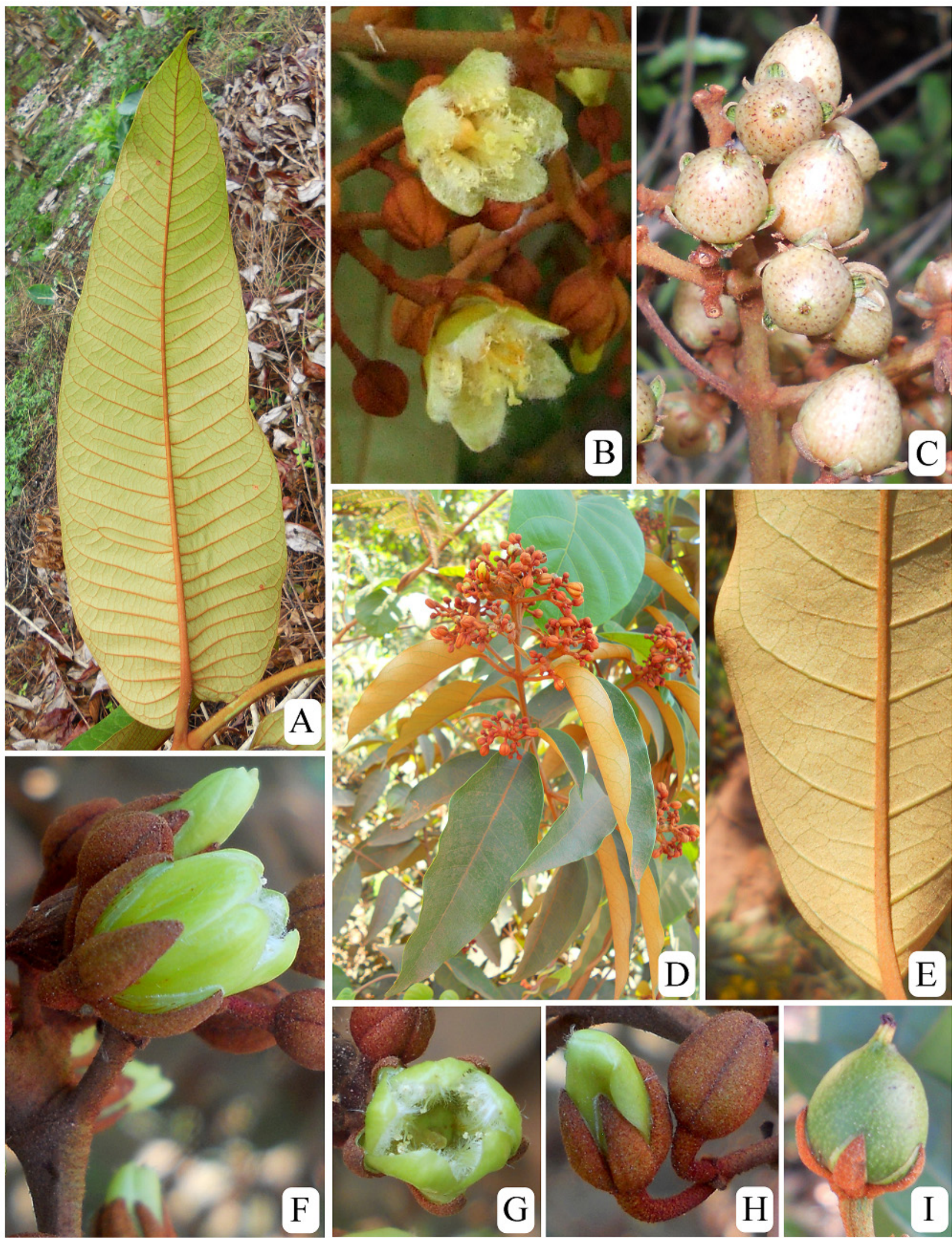

Figura 5. A-C. Vismia atlantica: A- folha, vista abaxial; B- flores; C- frutos. D-I. V. guianensis: D- ramo com inflorescências jovens; Efolha, vista abaxial; F-H- botões florais e flores; I- fruto. (A, C- Marinho et al. 959; B- Cardoso et al. 1583; D-H- Marinho et al. 592; I- Marinho et al. 597; fotos L.C. Marinho, B-D- Cardoso).

Vismia guianensis apresenta grande variação morfológica, podendo apresentar lâminas foliares mais coriáceas e glabras em áreas mais secas e menos elevadas próximas ao litoral. Morfologicamente, 
assemelha-se a $V$. pentagyna, diferenciando-se pelas pétalas sem glândulas evidentes (Figura 5F-H), além de ramos e folhas com coloração mais escura do que em $V$. pentagyna. Na Bahia, apenas $V$. guianensis apresenta flores heterostilas (Figura 3L, M).

\subsection{Vismia martiana Reichardt in Mart., Eichler \&} Urb., Fl. Bras. 12(1): 204; pl. 37. 1878.

Figuras 6, 7A-J e 9A-F.

Arvoretas ou arbustos até $10 \mathrm{~m}$ alt.; ramos esbranquiçados com tricomas ferrugíneos estrelados esparsos, pubescentes quando jovens, exsudato alaranjado. Folhas com pecíolo 8-30 mm compr.; lâmina $6,5-13,5 \times 2,5-7 \mathrm{~cm}$, cartácea, oval a elíptica, margens inteiras, ápice agudo a acuminado, base arredondada a atenuada, face adaxial verde in vivo, marrom-claro in sicco, face abaxial ferrugínea in vivo, marrom-escura in sicco, nervuras secundárias (11-16 pares) e intersecundárias pouco proeminentes, inconspícuas in sicco, velutina, com tricomas dendríticos e estrelados, glândulas nigrescentes cobertas por tricomas na face abaxial. Flores homostilas; pedicelo ca. $6 \mathrm{~mm}$ compr.; sépalas 5-6× 2,5-3 mm, castanhas, com tricomas ferrugíneos, lanceoladas, ápice agudo, base truncada, canais glandulares enegrecidos visíveis na face adaxial, margem membranácea; pétalas $8-9 \times 4-4,5 \mathrm{~mm}$, amarelo-esverdeadas, lanceoladas a obovais, ápice arredondado, base atenuada; face adaxial vilosa, face abaxial com canais e/ou pontuações glandulares castanhas; fascículos de estames 7-8 mm compr., com tricomas esparsos na base, não persistentes; nectários ca. $2 \mathrm{~mm}$ compr., ovais; estiletes 1,5-2 mm compr., geralmente persistentes, ovário $2,5-3 \mathrm{~mm}$ compr., oval a lanceolado. Bagas 0,8-1,2 cm compr., arredondadas a ovais; sépalas patentes no fruto maduro.

Vismia martiana ocorre comumente em áreas de mussununga e restinga no sul da Bahia. É também registrada para os estados do Espírito Santo, Minas Gerais, São Paulo e Rio de Janeiro (Bittrich et al. 2015). F8, G8, H8, I8, J8, H9: mussununga e restinga. Floresce de novembro a janeiro, com frutificação entre janeiro e maio.

Material selecionado - Alcobaça, Aparaju, $17^{\circ} 31^{\prime} \mathrm{S}, 39^{\circ} 11^{\prime} \mathrm{W}$, 6 fev. 2004 (fr.), L. Kollmann \& R.L. Kollmann 6519 (MBML); Belmonte, Barrolândia/Fazenda Liberdade, $15^{\circ} 51^{\prime}$ 'S, 38 $38^{\circ}$ 'W, 15 maio 1994 (fr.), M.L. Guedes et al. 3080 (ALCB, HUEFS); Cairu, 13²9'S, 3902'W, 14 ago. 1993 (est.), M.L. Guedes et al. s.n. (ALCB 25803); Caravelas, rodovia BR-418, 17 ${ }^{\circ} 43^{\prime} \mathrm{S}, 39^{\circ} 15^{\prime} \mathrm{W}, 18$. mar. 1978 (fr.), S.A. Mori et al. 9661 (CEPEC); Itacaré, Reserva

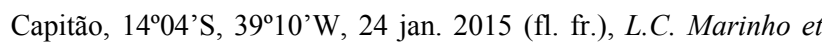
al. 951 (CEPEC); Itapebi, $12 \mathrm{~km}$ de Itapebi para Belmonte, $16^{\circ} 02^{\prime} \mathrm{S}, 39^{\circ} 28^{\prime} \mathrm{W}, 8$ jan. 2002 (fl. e fr.), T.S. Nunes et al. 783 (HUEFS); Porto Seguro, estrada para Eunápolis/CEPLAC, $16^{\circ} 23^{\prime} \mathrm{S}, 39^{\circ} 10^{\prime} \mathrm{W}, 15$ abr. 2003 (fr.), R.P. Oliveira et al. 881

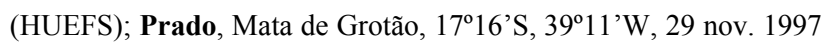
(fl.), M.L. Guedes \& M. Fonseca 5491 (ALCB, HUEFS); Santa Cruz Cabrália, Veracruz, 16 ${ }^{\circ} 16^{\prime}$ S, 3901'W, 17 nov. 2001 (fl.), L.M. Pacheco 60 (ALCB, CEPEC).

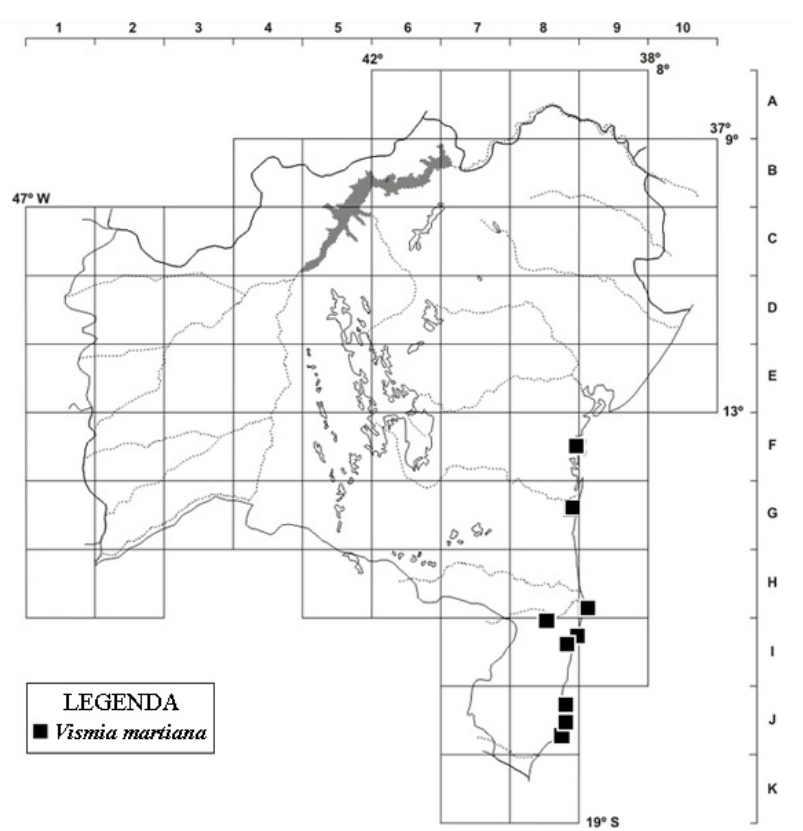

Figura 6. Mapa de distribuição geográfica de Vismia martiana no estado da Bahia.

Vismia martiana diferencia-se das demais espécies da Bahia pelas lâminas foliares com face abaxial velutina, muitas vezes recobrindo as pontuações glandulares e as nervuras secundárias (Figura 7B). Reichardt (1878) descreve as sépalas persistentes no fruto como reflexas, porém a ilustração nesta obra, bem como a coleção-tipo (barcode M0112257), mostram as sépalas tanto reflexas quanto patentes. Contrapondo os materiais da Bahia (Figuras 7D, E e 9C, D) e Ewan (1962), Reichardt (1878) relata não haver canais glandulares nas sépalas de $V$. martiana. Apesar de alguns materiais da coleção-tipo (Martius 890) mostrarem sépalas com face abaxial homogeneamente escura, ainda não se sabe se todos os síntipos pertencem à mesma espécie.

2.4. Vismia pentagyna (Spreng.) Ewan, Contr. U.S. Natl. Herb. 35(5): 352. 1962.

= Vismia decipiens Schltdl. \& Cham., Linnaea 3: 116.

1828 , nom. illeg.

Figuras $7 \mathrm{~K}-\mathrm{P}, 8$ e $9 \mathrm{G}-\mathrm{J}$.

Arbustos até $2 \mathrm{~m}$ alt.; ramos pubescentes com tricomas ferrugíneos estrelados, exsudato amarelo a alaranjado. Folhas com pecíolo 7-12 mm compr.; lâmina 5,5-12 × 2-5,3 cm, cartácea, elíptica a oval, margens inteiras, ápice acuminado a agudo, base arredondada a atenuada, face adaxial verde-clara in vivo, marrom-clara in sicco, face abaxial ferrugínea a creme in vivo, creme in sicco, nervuras secundárias (10-12 pares) e intersecundárias pouco proeminentes, tomentosa, com tricomas dendríticos e estrelados, e glândulas nigrescentes na face abaxial, com maior concentração na margem. Flores homostilas; pedicelos 3-4 mm compr.; sépalas 5-6 × 2-3,5 mm, creme, com tricomas creme a ferrugíneos, lanceoladas, ápice agudo, base truncada, 3-5 canais glandulares, pouco 


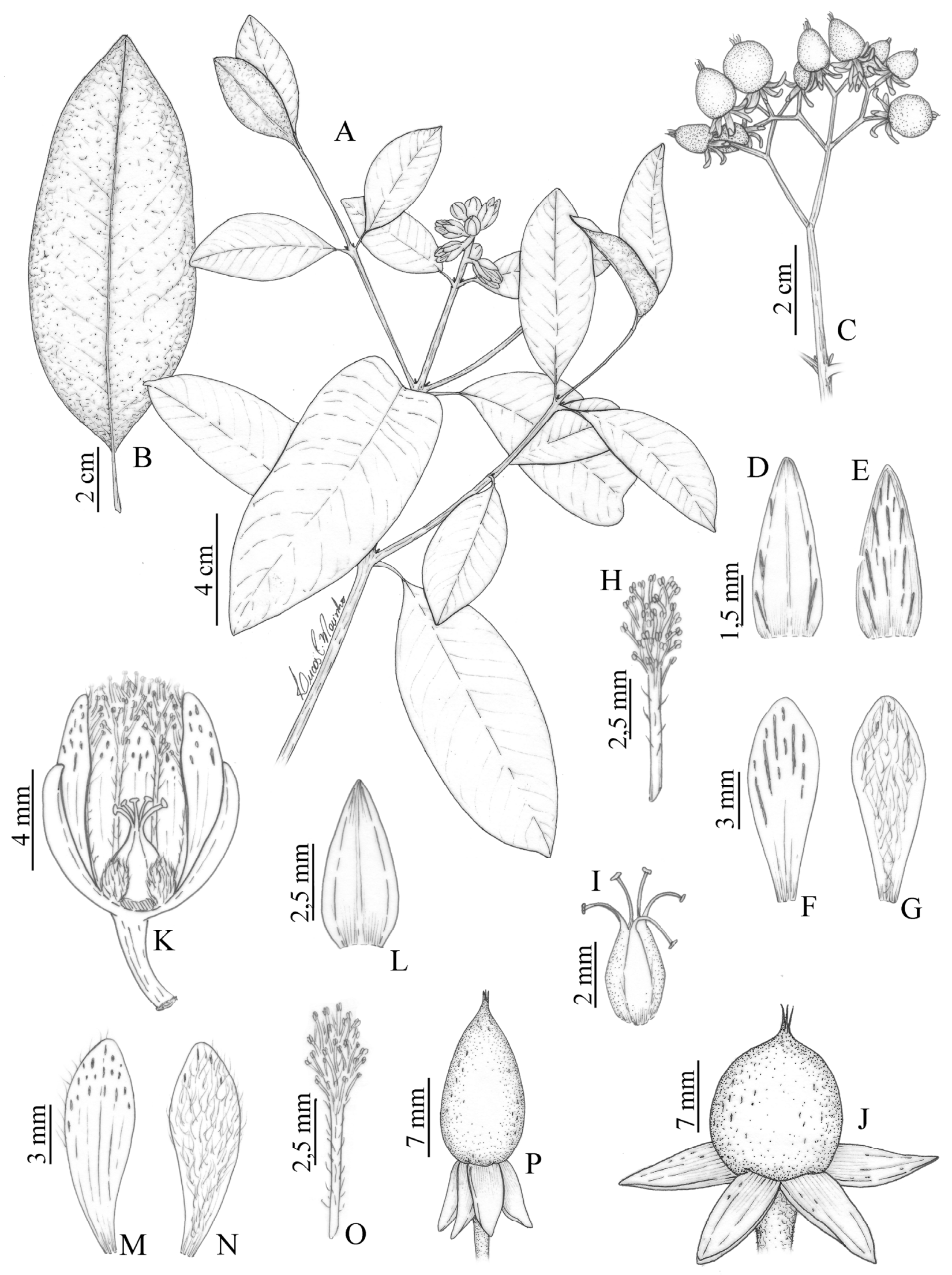

Figura 7. A-J. Vismia martiana: A- ramo com inflorescências; B- folha, vista abaxial; C- infrutescência; D- sépala, vista adaxial; E- sépala, vista abaxial; F- pétala, vista abaxial; G- pétala, vista adaxial; H- fascículo de estames; I- Gineceu; J- fruto. K-P. V. pentagyna: K- flor com duas sépalas e pétalas retiradas; L- sépala, vista abaxial; M- pétala, vista abaxial; N- pétala, vista adaxial; O- fascículo de estames; P- fruto. (A, B, J- Marinho et al. 951; C-I- Nunes et al. 783; K-O- Marinho et al. 597; P- Thomas et al. 11575). 


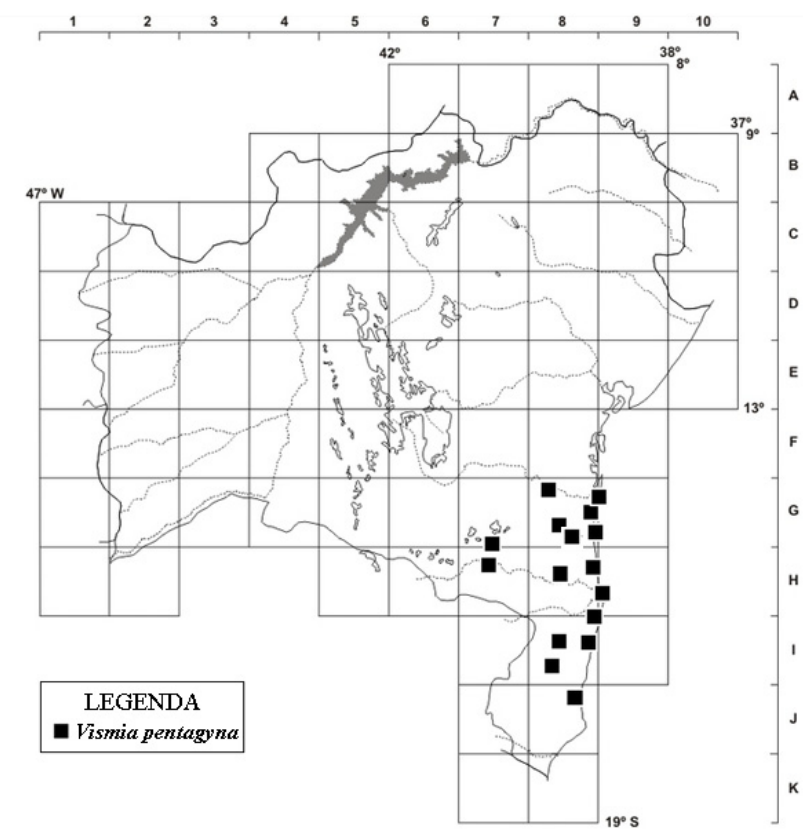

Figura 8. Mapa de distribuição geográfica de Vismia pentagyna no estado da Bahia.

evidentes in vivo; pétalas $7-9 \times 3-4 \mathrm{~mm}$, creme a esverdeadas, contortas, elípticas a lanceoladas, ápice arredondado a agudo, base atenuada, face adaxial vilosa, face abaxial com canais e pontuações glandulares castanhas; fascículos de estames 5-10 mm compr., com tricomas esparsos na base, não persistentes; nectários ca. $2 \mathrm{~mm}$ compr., ovais; estiletes 1-4 mm compr., geralmente persistentes, ovário 2,5$3,5 \mathrm{~mm}$ compr., oval. Bagas $1-1,2 \mathrm{~cm}$ compr., arredondadas a estreitamente ovais; sépalas reflexas no fruto maduro.

Vismia pentagyna é registrada para os estados da Bahia (Bittrich et al. 2015) e Goiás (Medeiros 2011). H7, G8, H8, I8, J8: floresta ombrófila montana, de terras baixas e floresta estacional semidecidual. Sua floração ocorre entre janeiro e maio, com frutos vistos até outubro.

Material selecionado - Almadina, Serra do Corcovado/São Domingos, $14^{\circ} 41^{\prime} \mathrm{S}, 39^{\circ} 34^{\prime} \mathrm{W}, 25$ jan. 2014 (fl.), L.C. Marinho et al. 597 (CEPEC, HUEFS); Barra do Choça, estrada para Itapetinga, 1457'S, 40³1'W, 30 mar. 1977 (fl.), R.M. Harley 20189 (CEPEC); Barro Preto, Serra da Pedra Lascada, $14^{\circ} 46^{\prime}$ 'S, $39^{\circ} 12^{\prime} \mathrm{W}, 21$ maio 2006 (fl.), M.M.M. Lopes et al. 687 (CEPEC); Belmonte, estrada para Itapebi, 1600'S, 3903'W, 24 mar. 1974 (fl.), R.M. Harley

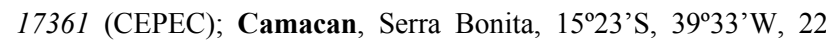
jan. 2007 (bot.), R.A.X. Borges 659 (CEPEC, HUEFS); Canavieiras, rodovia Canavieiras/Santa Luzia, $15^{\circ} 40^{\prime} \mathrm{S}, 38^{\circ} 56^{\prime} \mathrm{W}$, 15 jun. 1988 (fr.), L.A. Mattos-Silva et al. 2431 (CEPEC, HRB,

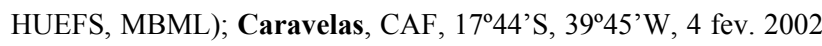
(bot.), M.L. Guedes et al. 9745 (ALCB); Eunápolis, Paraju II,

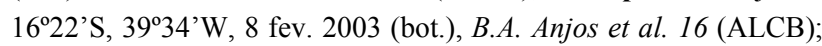
Guaratinga, Cajuíta, $16^{\circ} 43^{\prime}$ 'S, 3940'W, 8 fev. 1985 (fl.), A. Gentry \& E. Zardini 49940 (CEPEC); Ilhéus, Olivença, 1447'S, 3902'W, 17 mar. 1999 (fl.), L.A. Mattos-Silva et al. 3898 (HUEFS, HUESC); Itacaré, estrada para Ubaitaba, $14^{\circ} 16^{\prime}$ 'S, 38 $59^{\circ}$ 'W, 7 jun. 2000 (fr.), A.M. Amorim et al. 3427 (CEPEC); Itagibá, Mata do Cacau,

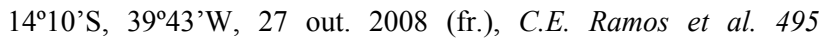
(ALCB); Porto Seguro, Parque Nacional Monte Pascoal, $15^{\circ} 15^{\prime} \mathrm{S}$, 40³4'W, 25 mar. 1996 (bot.), W.W. Thomas et al. 11170 (CEPEC, HRB, HUEFS); Prado, Parque Nacional do Descobrimento, 17 $11^{\prime}$ 'S, 39²0'W, 11 jun. 2009 (fr.), F.B. Matos et al. 1699 (CEPEC); Santa Cruz Cabrália, Estação Ecológica Pau-Brasil, 162ㄱ'S, 398'W, 15 fev. 1984 (fl.), F.S. Santos 263 (CEPEC, HRB, HUEFS); Santa Luzia, estrada para Canavieiras, 12 jul. 1964 (fr.), CMM s.n. (CEPEC 2162); Una, REBIO Una, $15^{\circ} 17^{\prime} \mathrm{S}, 39^{\circ} 04^{\prime} \mathrm{W}, 20$ jul. 1998 (fr.), A. Martini \& G. Santos 20 (ALCB, HUEFS, HUESC); Uruçuca, Serra Grande, 142ㅇ's, 396'W, 21 abr. 2004 (fl.), A.M. Amorim et al. 3978 (CEPEC).

Vismia pentagyna pode ser distinguida das demais espécies do gênero na Bahia pelo porte menor e a coloração mais clara dos ramos e folhas (Figura 9GH). Em algumas áreas, a espécie ocorre em simpatria com $V$. guianensis, diferindo desta pelas pétalas notadamente glandulares (canais e pontuações; Figura 9J). Os canais glandulares nas sépalas de $V$. pentagyna são pouco evidentes in vivo, apresentando uma coloração alaranjada. In sicco, estes canais se tornam mais visíveis e sua presença pôde ser confirmada pela análise de um de seus sintipos na coleção W (0061549).

\section{AgradeCIMENTOS}

Ao CNPq, pelas bolsas de Doutorado concedida a LCM (141561/2015-7) e Produtividade em Pesquisa concedida a AMA (310717/2015-9) e pelo financiamento dessa pesquisa (Edital Reflora Malpighiales 563548/2010-0, Edital Universal 486079/2013-9 e pelo Edital PPBIO 457483/2012-1). À MSc. Cleusa Vogel Ely e ao Dr. Volker Bittrich pelas valiosas contribuições; e à equipe do herbário CEPEC pelo apoio logístico.

\section{REFERÊNCIAS}

Bittrich, V.; Trad, R.J.; Cabral, F. \& Nascimento-Jr, J. E. 2015. Hypericaceae. In: Lista de Espécies da Flora do Brasil. Jardim Botânico do Rio de Janeiro. Disponível em: http://reflora. jbrj.gov.br/jabot/floradobrasil/FB133; acesso em: 15 dez. 2015.

Ewan, J. 1962. Synopsis of the South American species of Vismia (Guttiferae). Contributions from the United States National Herbarium 35(5): 293-377.

Kearns, D.M.; Berry, P.E.; Stevens, P.F.; Cuello, N.L.; Pipoly, J.P.; Robson, N.K.B.; Holst, B.K.; Kubitzki, K. \& Weitzman, A.L. 1998. Clusiaceae. In: J.A. Steyermark, P.E. Berry \& B.K. Holst (eds), Flora of the Venezuelan Guayana. Vol. 4. Missouri Botanical Garden Press, St. Louis, p. 248-329.

Marinho, L.C.; Martins, M.V.; Amorim, A.M. \& Bittrich, V. 2016. Vismia atlantica (Hypericaceae), a new species previously thought to be well-known from the Brazilian Atlantic Forest. Journal of the Torrey Botanical Society 143(3): 330-337.

Medeiros, J.D. 2011. Guia de Campo: vegetação do Cerrado 500 espécies. Ministério do Meio Ambiente/SBF, Brasília. 


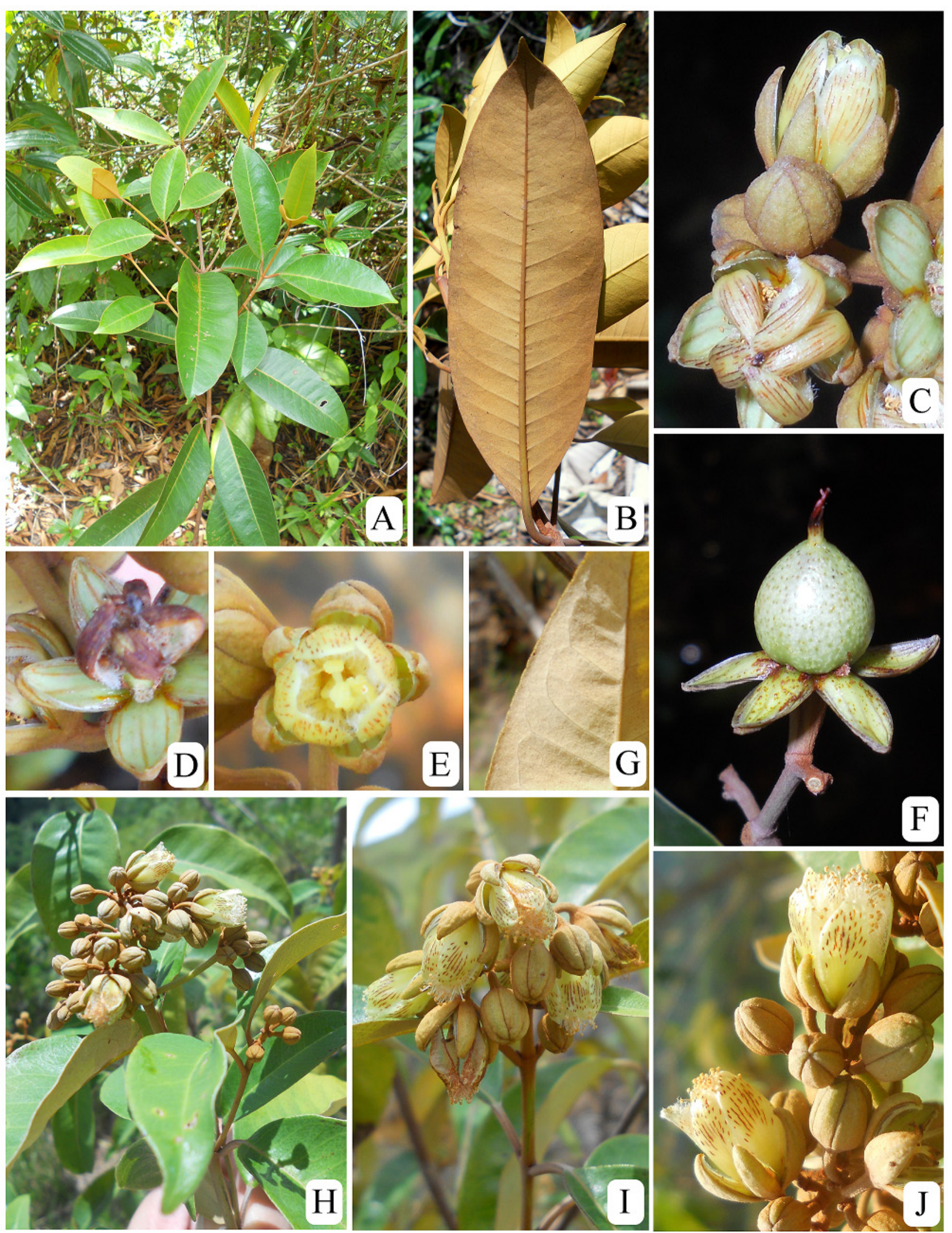

Figura 9. A-F. Vismia martiana: A- ramo com folhas, vista adaxial; B- folha, vista abaxial; C-E- botões e flores; F- fruto. G-J. $V$. pentagyna: G- folha, vista abaxial; H- ramo com botões florais e flores; I-J- botões e flores. (A-F- Marinho et al. 951; G-I- Marinho et al. 597; fotos L.C. Marinho).

Meseguer, A.S.; Aldasoro, J.J. \& Sanmartin, I. 2013. Bayesian inference of phylogeny, morphology and range evolution reveals a complex evolutionary history in St. John's wort (Hypericum). Molecular Phylogenetics and Evolution 67: 379-403. 
Reichardt, H.G. 1878. Hypericaceae. In: C.F.P. Martius, A.G. Eichler \& I. Urban (eds), Flora Brasiliensis. Vol. 12. Frid. Fleischer, Lipsiae, p. 182-212.

Robson, N.K.B. 2012. Studies in the genus Hypericum L. (Hypericaceae) 9. Addenda, corrigenda, keys, lists and general discussion. Phytotaxa 72: 1-111.

Stevens, P.F. (2016). Angiosperm Phylogeny Website. Versão 12, Julho 2012 [and more or less continuously updated since]
Disponível em: http://www.mobot.org/MOBOT/research/ APweb/; acesso em: 15 abr. 2016.

Vogel Ely, C. \& Boldrini, I.I. 2015. A new threatened species of Hypericum from the South Brazilian Pampa biome. Systematic Botany 40(4): 989-994.

Vogel Ely, C.; Boldrini, I.I. \& Bordignon, S.A.L. 2015. A new species of Hypericum (Hypericaceae) from Southern Brazil. Phytotaxa 192(4): 290-295.

\section{LISTA DE EXSICATAS}

Almeida, L.S. 10 (2.1); Alunos Bot. III. s.n. CEPEC 82411 (2.2); Alves, L.J. 36 (2.3), 101, 412 (2.2); Alves, M. 1151 (2.2); Alves, M.B.B. 10 (2.2); Amaral, M.C.E. 8388 (2.3); Amorim, A.M. 611 (2.1), 1080 (2.2), 1090 (2.4), 1381 (2.1), 1770 (2.2), 1972 (2.4), 2003 (2.1), 2124 (2.2), 3427 (2.4), 3972 (2.1), 3978 (2.4), 6481 (2.3), 6669 (2.1), 6962 (2.4), 7659 (2.2), 7894 (2.1); Andrade, M.J.G. 249 (2.2); Anjos, A.C. 24 (2.2); Anjos, B.A. 16 (2.2); Araújo, J.S. 131 (2.2); Arouck, J. 141 (2.2); Batista, M.A. s.n. ALCB 47498, CEPEC 85761 (2.2); Bautista, H.P. 1139 (2.3), 1162 (2.2), 1210, 3001, 3047, 3076, 3116 (2.2); Bélem, R.P. 662 (2.2), 849 (2.4), 1398 (2.1), 2155,2259 (2.2), 2647 (2.1), 3126 (2.2), 3268 (2.3); Borges, R.A.X. 659 (2.4); Brito, H.S. 160 (2.2), 260 (2.4); Brito, T.H. 3988 (2.4); Campos, G.S. 68 (2.2); Cardoso, D. 1132 (2.2), 1583 (2.1), 1704 (2.2); Carneiro-Torres, D.S. 197 (2.2); Carvalho, A.M. 373 (2.1), 634 (2.2), 3653 (2.1); Carvalho, G. 24 (2.2); Carvalho, G.M. 122 (2.2), 230, 339 (2.4); Carvalho, P.D. 296 (2.2); Carvalho-Sobrinho, J.G. 123, 191 (2.2); Castro, M.S. 601 (2.2); C.M.M. 92 (2.1), s.n. CEPEC 2162 (2.4); Conceição, A.S. 221 (2.2); Correia, S. s.n. ALCB 55224 (2.2); Costa, A.L. 227, 852, 896, s.n. ALCB 2789, ALCB 2790, ALCB 2792, ALCB 2793, ALCB 2794, ALCB 19303, ALCB 19687, HUEFS 15472, HUEFS 15471, HUEFS 15474 (2.2); Costa, G. 508 (2.2); Costa, J. 253 (2.2); Costa, M.A.A. 129 (2.2); Costa-Neto, E.M. 8 (2.2); Couto, A.P.L. 8, 181, 214 (2.2); Daneu, L. 207, 214 (2.1), 314 (2.4); Euponino, A. 44 (2.3), 237, 488 (2.4), 502 (2.3); Folli, D.A. 684 (2.4), 720 (2.2), 840 (2.3); Fraga, C.N. 2582 (2.2); França, F. 1094 (2.2), 3376 (2.4), 3967, 4758, 5432 (2.2); Freire, L. 19 (2.2); Fonseca, M. 935 (2.3); Fonseca, M.R. 70 (2.2); Fonseca, W. 291 (2.2); Funch, L.S. 121, 124, 185 (2.2); Funch, R. 54 (2.2); Gentry, A. 49940 (2.4); Gomes, F.S. 522, 628, 798, 902 (2.2); Grupo Botânica III. 5 (2.4); Guaré, F. s.n. ALCB 75136 (2.2); Guedes, M.L. 159, 1234, 1444 (2.2), 2582, 2981 (2.1), 3080 (2.3), 3142 (2.1), 3219 (2.4), 3368, 4123 (2.2), 5301 (2.3), 5347 (2.2), 5491 (2.3), 6611, 6651 (2.2), 6728 (2.3), 7461 , 8283, 8866, 9374 (2.2), 9388, 9452 (2.1), 9745 (2.4), 9759 (2.2), 9996 (2.3), 10065, 10778, 11175, 11395, 13026, 13252, 14715 (2.2), 16445, 16480 (2.4), 16907 (2.3), 18004, 19356, 19776, 19806 (2.2), 20047, s.n. ALCB 25803 (2.3), ALCB 76766 (2.2); Hage, J.L. 117 (2.3), 399 (2.1), 790 (2.4), 1694 (2.2); Harley, R.M. 5988, 16593 (2.2), 17192, 17361 (2.4), 17598 (2.2), 17890 (2.3), 18133 ( 2.4), 18532, 18576, 18891, 20557 (2.2), 20173 (1.1), 20189 (2.4), 22039 (2.2); Hatschbach, G. (2.1); Jesus, N.G. 132, 140 (2.1), s.n. HUESC 13590 (2.4), HUEFS 145225 (2.2); Jost, T. 125, 304, 663 (2.2); Kollmann, L. 6519 (2.3); Lanna, J.P. 733 , 1346 (2.4), 1558 (2.1); Lewis, G.P. 1168 (2.2); Lilio, R. 26 (2.4); Lima, D.P. 13090 (2.1); Lima, J. s.n. ALCB 61468 (2.2); Lima, L.C.L. 79 (2.2); Lima, L.C.P. 414 (2.2); Lima, M.P.M. 358 (2.2); Lima, R. 2320 (2.2); Lima, S.S. 26 (2.4); Loizeau, P.A. 521 (2.2); Lopes, M.M.M. 629, 687, 867, 922 (2.4); Lucas, E.J. 1100 (2.1); Maas, P.J.M. 7031 (2.3); Marinho, L.C. 548, 592 (2.2), 597 (2.4), 951 (2.3), 959, 1071, 1072 (2.1); Martineli, G. 11054 (2.2); Martini, A. 20, 94 (2.4), 97 (2.1), 181 (2.4); Matos, E. 296, 687 (2.2), 710 (2.1), 987, 1007, 2708 (2.3); Matos, F.B. 1699 (2.4), 1705 (2.3), 1763 (2.4); Mattos-Silva, L.A. 311 (2.1), 319 (2.2), 337, 374 (2.4), 609 (2.1); 1122 (2.2), 1405, 2431 (2.4), 2443,3525 (2.1), 3898 (2.4), 3901 (2.2), 3907 (2.4), 4414, 4517, 4580 (2.2), 4677 (2.4), 4746, 4858 (2.2), 4879 (2.4), 5063 (2.1), 5173 (2.4); Melo, E. 2608, 8990, 9994 (2.2); Miranda, A.M. 5166 (2.1); Miranda, A.S. 39 (2.4); Miranda, E.B. 67 (2.2); Moraes, M.V. 499 , 778 (2.2); Mori, S.A. 9661 (2.3), 9797, 9826 (2.4), 10165 (2.2), 10957 (2.3), 13103 (2.2); Moutinho, L. 7 (2.2); Neves, D.M. 1567 (2.2); Neves, M. 207 (2.2); Noblick, L.R. 1815, 2243, 3326 (2.2); Nunes, A.T. 22, 72 (2.2); Nunes, T.S. 361, 783 (2.3), 1294, 1322 (2.2); Oliveira, I. 31 (2.2); Oliveira, P.P. 10 (2.2); Oliveira, P.R.C. 5 (2.2); Oliveira, R.P. 881 (2.3), 1464 (2.2); Orlandi, R.P. 337 (2.2); Pacheco, L.M. 21 (2.2), 60 (2.3); Paganucci, L. s.n. ALCB 8484 (2.2); Paixão, J.L. 934, 857 (2.4), 1159, 1166 (2.2); Pereira, P.A. 59 (2.4); Pereira-de-Sousa, P. s.n. ALCB 2795, ALCB 10738, ALCB 10739, HRB 10739 (2.2); Pigozzo, C.M. 225 (2.2); Pinto, G.C.P. $32 / 92$ (2.2); Pirani, J.R. 2366 (2.4); Popovkin, A.V. 150, 203 (2.2); Prates, A.R. 195 (2.2); Queiroz, E.P. 376, 421, 565, 640, 874, 876, 1119, 2962, 3671, 3919 (2.2); Queiroz, L.P. 1218, 1449, 1585, 1879, 3772, 5503, 6282, 7690 (2.2); Querino, R.N. 11 (2.1), 23 (2.2); Ramos, C.E. 66 (2.4), 182 (2.2), 495 (2.4); Rezende, S.G. 1732 (2.2); Ribeiro, A.J. 427 (2.1); Ribeiro, T. 508, 511 (2.2); Ribeiro-Filho, A.A. 165 (2.2); Roque, N. FCO 114, 531, 2603, 4017, 4114 (2.2); Russ, B.R. 11 (2.2); Rylands, A. 22/1980 (2.1); Saar, E. 24, 5608 (2.2); Sambuichi, R.H.R. 1380a, s.n. CEPEC 89165 (2.1); Santana, C.A.S. 18 (2.2); Santana, D.L. 271 (2.2), 763 (2.1); Sant'Ana, S.C. 895 (2.4); Santos E.A. 40, 72 (2.2); Santos, F.S. 169 (2.3), 263 (2.4), 477 (2.3), 495 (2.2), 662 (2.3), 848, 934 (2.4); Santos, L.B.E. 520 (2.3); Santos, R.B. 24,34 (2.2); Santos, T.S. 1082 (2.1), 1523 (2.4), 2179, 2446, 2705 (2.1), 2909 (2.2), 3315, 3861 (2.1), 3988 (2.4); 4578 (2.2), 4580 (2.1), 4582 (2.4); Santos, V.J. 458 (2.2); Sarmento, A.C. 874 (2.2); Sellow, F. s.n. W 0061549 (2.4); Senna, L.R. 15 (2.2); Silva, B.M. 27 (2.2); Silva, M.M. 63 (2.2); Silva, P.E.M.A. 26 (2.2); Silva-Lima, C.S. 117 (2.2); Sobral, M. 5512 (2.2), 5556 (2.1); Sobrinho, J.G.C. 6 (2.2); Soeiro, R. 60 (2.2); Sousa, L.A. 61, 248 (2.2); Souza, E.B. 1442 (2.2); Souza, E.R. 454 (2.2); Souza, J.F. s.n. HUEFS 15473 (2.2); Souza, M.C. 387 (2.1); Souza, P. 10739 (2.2); Stradmann, M.T.S. 531, 739 (2.2); Thomas, W.W. 8926 (2.2), 11170 (2.4), 11340 (2.1), 11341 (2.3), 11498,11575 (2.4), 12768 (2.1), MT574 (2.3); Torrenol, C. s.n. ALCB 2797 (2.2); Valadão, R. 508 (2.2), 728 (2.1); Vieira, L.P. 64 (2.2); Vinhas, S.G. 96 (2.2); Woodgyer, E. 2342, 2766 (2.2). 